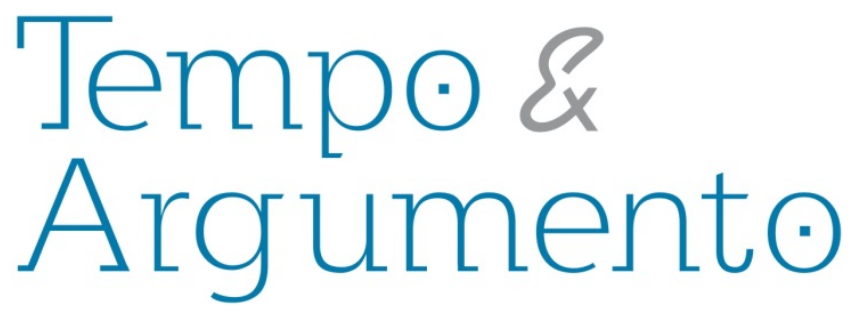

\title{
Escrever textos, editar livros, fazer história: a coleção documentos brasileiros e as transformações da historiografia nacional (1936-1960)
}

\begin{abstract}
Resumo
Este artigo apresenta um panorama do período áureo da Coleção Documentos Brasileiros, mostrando como, entre as décadas de 1930 e 1950 - momento em que vários outros projetos semelhantes se desenvolveram no sentido de "pensar o País" -, ela abrigou autores e obras comprometidos com a produção de um novo conhecimento sobre o Brasil, em especial no que diz respeito à história. Justamente por isso, este empreendimento editorial configurou-se também como um veículo privilegiado para a difusão de novas formas de abordar o nosso passado, desempenhando, assim, um importante papel no cenário de transformações pelas quais passava então a historiografia nacional.
\end{abstract}

Palavras-chave: Coleção Documentos Brasileiros. Historiografia brasileira. Escrita da História.

\author{
Fábio Franzini \\ Doutor em História Social. Professor \\ do Departamento de História da \\ Universidade Federal de \\ São Paulo - UNIFESP. \\ fabio.ff.franzini@gmail.com
}

\footnotetext{
Para citar este artigo:

FRANZINI, Fábio. Escrever textos, editar livros, fazer história: a coleção documentos brasileiros e as transformações da historiografia nacional (1936-1960). Revista Tempo e Argumento, Florianópolis, v. 5, n.9, jan./jun. 2013. p. 24 - 45.
}

DOI: $10.5965 / 2175180305092013024$

http://dx.doi.org/10.5965/2175180305092013024 


\title{
Writing texts, editing books, making history: the 'Coleção Documentos Brasileiros' and the changing of national historiography (1936-1960)
}

\begin{abstract}
This article presents an overview of the Coleção Documentos Brasileiros' golden age (from the 1930 s to the 1950s, contemporaneously to other similar projects) and intends to show how it housed authors and books committed to the production of a new knowledge about Brazil, particularly as regards to the History. Thus this editorial enterprise has set up also a privileged vehicle to the diffusion of new ways to approach the Brazilian past, playing an important role in the transforming scenario whereby the Brazilian historiography then was passing.
\end{abstract}

Keywords: Coleção Documentos Brasileiros.

Brazilian historiography. Writing of History.

Gilberto Freyre, Sérgio Buarque de Holanda, Octavio Tarquínio de Sousa, Afonso Arinos de Melo Franco e Pedro Calmon; Luis Viana Filho, João Camilo de Oliveira Torres e Lúcia Miguel-Pereira; Francisco de Assis Barbosa, Luis da Câmara Cascudo e Affonso d’Escragnolle Taunay. Não se trata de um time de futebol, é evidente, mas nem por isso 
esses nomes deixam de formar uma seleção: uma seleção de autores que, longe de se limitar aos 11 citados, deu forma e vida a um dos mais marcantes projetos editoriais brasileiros e que, ao fazê-lo, muito contribuiu para mudar as formas de se escrever, ler e pensar a história entre nós - a Coleção Documentos Brasileiros, da Livraria José Olympio Editora.

Inaugurada em 1936, a Documentos Brasileiros avançou pelo século XX até a década de 1980, abrigando, sob a sua palmeira-símbolo, mais de duzentos títulos. A sua época áurea, contudo, concentra-se entre os anos 30 e 50, quando se constituiu no principal veículo de difusão das mais importantes reflexões então produzidas a respeito do passado e do presente do País. E isto não era pouca coisa, em especial porque ela não estava sozinha no cenário editorial da época; ao contrário, as coleções dedicadas à análise dos problemas, das possibilidades e, sobretudo, da especificidade da nossa formação histórico-social foram um produto característico daquele momento, pensadas por diferentes editores justamente para abrigar o crescente e diversificado número de intérpretes e interpretações dedicados ao "conhecimento do Brasil”, como então se dizia (PONTES, 2001; CARONE, 2004).

Não por acaso, é difícil entender o surgimento da Documentos Brasileiros sem levar em consideração outra série contemporânea, de nome altamente sugestivo: a Coleção Brasiliana. Lançada pela Companhia Editora Nacional em 1931 e dirigida pelo respeitado educador Fernando de Azevedo, a Brasiliana apresentava-se em seus anúncios publicitários como "a mais vasta e a mais completa coleção e sistematização que se tentou até hoje de estudos brasileiros", reunindo "ensaios sobre a formação histórica e social do Brasil, estudos de figuras e de problemas nacionais (geográficos, etnológicos, políticos, econômicos, militares, etc.), reedições de obras raras de notório interesse e traduções de obras estrangeiras sobre assuntos brasileiros". Em termos concretos, isto significava publicar autores conhecidos e novos, clássicos e contemporâneos, nacionais e estrangeiros, bem como trabalhos tanto originais quanto reeditados, numa atividade intensa a ponto de atingir a impactante marca de cem volumes lançados em pouco mais de cinco anos. 
Tal inegável sucesso decerto estimulou outros editores a seguirem a trilha aberta pela Nacional, como efetivamente aconteceu; entretanto, para entender melhor a sua influência e, em especial, a inspiração particular que provocou em José Olympio, há que se matizá-lo. Junto aos intelectuais, a Brasiliana adquiriu prestígio inconteste, como se pode perceber na página e meia de opiniões publicada no Anuário Brasileiro de Literatura de 1938, em comemoração aos cem números editados. Em meio a considerações mais elaboradas e a outras nem tanto, talvez a mais expressiva seja a de Nelson Werneck Sodré, então crítico do Correio Paulistano, para quem a série representava "um dos acontecimentos mais notáveis da vida mental do país. Esse esforço único, que constitui uma realização integral de programa bem delineado, marca uma época nos estudos das coisas nacionais" (ANUÁRIO, 1938, p. 304).

Os leitores "comuns", em contrapartida, pareciam ainda não ter desenvolvido a mesma sensibilidade. Em resposta à enquete promovida pelo mesmo Anuário (1938, p. 407) para saber o que então se lia no Brasil, um porta-voz da editora avaliava que a "elite apreciadora dos trabalhos de cultura" acompanhava com interesse o desenvolvimento da coleção; apesar de seu "animador aumento nestes últimos tempos", ela ainda era "uma minoria" frente à "massa", cujas preferências recaíam sobre a "literatura de ficção, que distrai sem fazer pensar". "Mesmo assim, apesar de o descompasso entre públicos obviamente se refletir nas vendas, a empresa seguiu firme com seu projeto, comprometida antes com o lucro simbólico que com o lucro financeiro propiciado pela Brasiliana (PONTES, 2001, p. 450; HALLEWELL, 2005, p. 378-381).

Por paradoxal que possa parecer, para José Olympio esse valor simbólico falou mais alto que a caixa registradora ao pensar a sua própria coleção de estudos brasileiros. Afinal, tal como Monteiro Lobato, que na década anterior sonhara inundar o País com uma chuva de livros, ele também atribuía uma dimensão "civilizadora” ao seu trabalho tanto que faria famosa a frase lobatiana que adotara como lema de sua editora: "um país

\footnotetext{
${ }^{1}$ Complementando a sua avaliação, o representante da editora ainda dizia ser "plenamente justificável a tendência que a massa quase geral do público sente por este gênero de literatura. Diz um dos nossos mais eminentes críticos que este interesse vem da 'necessidade de sonho, a premência de distrair a mente na oscilação igual da vida cotidiana, a procura daquilo que eles não vivem, aquilo que está além dos limites das suas existências pacíficas e metodizadas" (ANUÁRIO, 1938, p. 407).
} 
diferencial, porém, estava no empenho com que levou adiante esse ideal, do qual nasceria, inclusive, a imagem heróica e mítica de um personagem acima do bem e do mal, cujos atos se explicavam sempre em nome do Brasil.

A concepção da Coleção Documentos Brasileiros, portanto, expressa muito do espírito da época e, em particular, dos interesses e ideais patrióticos de seu editor. Muito, entretanto, não é tudo, pois uma boa dose de tino para os negócios também a orientou desde sua idealização, a começar pela escolha de Gilberto Freyre para a sua direção. 0 jovem intelectual pernambucano, àquela altura já consagrado pelo sucesso avassalador de Casa-grande \& senzala, publicado havia apenas três anos, garantiria respeitabilidade e prestígio imediatos ao projeto, além de representar a "novidade" e a "brasilidade" que José Olympio tanto prezava em seus autores. Ao mesmo tempo, sua sólida formação intelectual asseguraria a avaliação criteriosa dos títulos a serem lançados e, por extensão, a solidez e a identidade da própria coleção.

Do ponto de vista de Freyre, a oferta era irrecusável. Não bastasse a considerável remuneração, ela também representava a oportunidade de ocupar uma posição privilegiada dentro de uma das principais editoras do País e, consequentemente, dentro do limitado circuito nativo de produção e circulação de ideias. Embora a empresa preservasse o direito de não publicar o que julgasse "sem base comercial", os termos do contrato lhe garantiam autonomia total na definição dos títulos, pois estabeleciam que nela só seriam editados os textos aprovados pelo diretor, sem impor qualquer outra condição ou restrição (VILLAÇA, 2001, p. 87-88). Na prática, isto não apenas abria um novo espaço para seus futuros livros, como, sobretudo, se configurava como uma possibilidade concreta de ampliar para além de sua própria obra os seus esforços, no sentido da renovação do conhecimento sobre o Brasil. Mais que um autor, ele agora assumia o papel de legitimador de outros autores, e não deixaria de aproveitá-lo para estabelecer um programa de ação centrado em seus próprios interesses intelectuais. 
A correspondência entre o Rio de Janeiro e Recife no decorrer de 1936 mostra bem como os interesses empresariais, acadêmicos e culturais se fundiam no projeto da coleção. ${ }^{2}$ Em 4 de julho, escrevendo a José Lins do Rego, recém-estabelecido na Capital, Gilberto discute o que parece ser uma sugestão do amigo, a inauguração da coleção com um livro do diplomata e historiador Alberto Rangel. "Acho ótimo", dizia ele, "um livro do Rangel na coleção, mas $01^{\circ}$ acho que deve ser o de Sérgio - por ser um estudo inteiro, sério e profundo sobre um só assunto, e por já figurar como o primeiro na introdução que escrevi e remeto por seu intermédio" (apud LIMA e FIGUEIREDO JUNIOR, 2000, p. 247). Sérgio, no caso, era Sérgio Buarque de Holanda, crítico literário, professor-assistente da cadeira de História Moderna e Contemporânea na recém-criada Universidade do Distrito Federal e seu velho amigo. Pelos elogios tecidos ao trabalho, pode-se perceber com clareza que seu valor estava em seu caráter monográfico e analítico, bem de acordo com os novos saberes esperados pelo diretor. Tão bem que, mesmo se tratando da obra de estreia de um autor novo, de pouco nome público, Gilberto Freyre Ihe havia assegurado de imediato o privilégio de abrir a Documentos Brasileiros, como se deduz do argumento pragmático com que encerra o assunto junto a José Lins.

Muito corajosa sob o aspecto editorial, a atitude parecia não deixar dúvidas sobre qual seria o espírito da série. Se ela causou temor em José Olympio, o editor soube disfarçá-lo muito bem, pois em nenhum momento da correspondência com Freyre deixa transparecer qualquer preocupação com um eventual fracasso comercial. Ao contrário, ele se envolve com entusiasmo na realização do projeto, com particular atenção aos autores e títulos que nele entrariam, incluindo o próprio responsável pela coleção, a quem escreve em 15 de julho apenas para perguntar como andava o livro em que então trabalhava, Nordeste. Sem rodeios, deixava claro que, "como você não pode deixar de imaginar, gostaria que fosse ele dos primeiros a sair dos 'Documentos Brasileiros”'.

\footnotetext{
2 As cartas trocadas entre os principais responsáveis pela Coleção Documentos Brasileiros, que serão citadas ao longo deste artigo, a partir deste ponto fazem parte da correspondência passiva de José Olympio e da Livraria José Olympio Editora, pesquisada no Arquivo-Museu de Literatura Brasileira da Fundação Casa de Rui Barbosa (Rio de Janeiro), e da correspondência passiva de Gilberto Freyre, pesquisada na Fundação Gilberto Freyre (Recife) - instituições às quais agradeço tanto pela preservação dessa rica e expressiva documentação quanto pelas condições de pesquisa que oferecem.
} 
Às vésperas do lançamento da coleção, José Olympio mal podia conter a expectativa. Em carta datada de 10 de outubro, ele não escondia a satisfação com o resultado de sua produção, e contava, com orgulho, ter mandado fazer "vinte exemplares fora de comércio, sendo dez para a Casa e dez para o autor, além dos que ele já tem [...] em papel comum". A capa também lhe agradara bastante, e tinha a certeza de que com Freyre não seria diferente. Por fim, mostrava-se feliz ainda porque a continuidade imediata da série estava garantida, com os originais das Memórias, de Oliveira Lima, já na tipografia e com publicação prevista até janeiro, juntamente com No rolar do tempo, de Alberto Rangel; em seguida, "ainda no primeiro trimestre de 37", sairia Memórias de um senhor de engenho, de Julio Bello, e, talvez, a biografia de Bernardo Pereira de Vasconcellos, escrita por Octavio Tarquínio de Sousa. Oliveira Vianna comunicara que não mais prepararia o livro esperado, mas ainda havia a "tradução magnífica” da Viagem a São Paulo, de Saint-Hilaire, feita por Rubens Borba de Morais e A. Couto de Barros.

Quando esta carta chegou ao Recife, os 3.000 exemplares de Raízes do Brasil, de Sérgio Buarque de Holanda, já estavam nas livrarias, ao preço de dez mil-réis cada. ${ }^{3}$ Como observara o editor, o aspecto material da obra era mesmo digno de elogio, em especial sua capa, feita pelo artista plástico Tomás Santa Rosa, notável colaborador da "Casa". Na cor clara do papel-cartão característico das encadernações da época e com as letras em um suave tom de marrom, ela trazia no topo o nome da coleção e, separada por um filete verde e em corpo um pouco menor, a inscrição “dirigida por Gilberto Freyre”, seguida do número do volume e do nome do autor; pouco abaixo, quase no meio da folha, o título do livro, este em grandes, porém proporcionais, letras verdes. No exato centro da página não havia nada, mas a sensação de vazio era evitada pelo desenho de uma discreta palmeira, o símbolo da coleção, que, no mesmo tom de marrom das letras, dominava praticamente toda a sua metade inferior, completada pelo sinete "Livraria José Olympio

3 Apenas para efeito comparativo e, assim, referencial do valor do livro no momento de seu lançamento, cabe notar que no Rio de Janeiro, à época, a "Tabela de preços máximos para a venda à vista ou à prazo dos gêneros de primeira necessidade no comércio a varejo do Distrito Federal”, em vigor desde 21 de setembro de 1936, estabelecia preços como 900 réis para o quilo do feijão preto, dois mil-réis para o quilo da carne "de primeira qualidade" e mil-réis para o litro de leite fresco, entregue em domicílio (DIARIO OFFICIAL, 19/09/1936, p. 20673-20674). 
Editora". Diferentemente da Brasiliana, cujas capas chamativas eram tomadas por um mapa do Brasil pontilhado de estrelas, em cores que variavam para cada título da série, a primeira impressão que se tinha do livro era a de equilíbrio e objetividade - o mesmo que o leitor, ao abri-lo, encontraria reivindicado para a coleção no prefácio de Gilberto Freyre.

O texto de Freyre, intitulado justamente "Documentos Brasileiros", principiava por vinculá-la ao momento vivido pela intelectualidade nacional. Buscando no contexto a sua legitimação, ele ressaltava ainda o papel e a importância de José Olympio no cenário das transformações que então ocorriam. Em suas palavras, a série surgia para:

trazer ao movimento intelectual que agita o nosso país, à ânsia de introspecção social que é um dos traços mais vivos da nova inteligência brasileira, uma variedade de material, em grande parte ainda virgem. Desde o inventário à biografia; desde o documento em estado quase bruto à interpretação sociológica em forma de ensaio. $O$ característico mais saliente dos trabalhos a ser [sic] publicados nesta coleção será a objetividade. Animando-a, o jovem editor José Olympio mais uma vez se revela bem de sua geração e do seu tempo. Ao interesse pela divulgação do novo romance brasileiro ele junta agora o interesse pela divulgação do documento virgem e do estudo documentado que fixe, interprete ou esclareça aspectos significativos da nossa formação ou da nossa atualidade. Não podia ser mais oportuna nem mais feliz a sua iniciativa (FREYRE in HOLANDA, 1936, p. V).

Sobre o volume de estreia, ele dizia representar a "afirmação vitoriosa" das “qualidades" e do "gosto" de seu autor, "uma daquelas inteligências brasileiras em que melhor se exprimem não só o desejo como a capacidade de analisar, o gosto de interpretar, a alegria intelectual de esclarecer". Todavia, como o intuito daquela apresentação não era falar do livro, a voz autorizada do diretor rapidamente voltou ao plano geral da Documentos Brasileiros. Primeiro, destacava não se tratar "de uma aventura editorial, mas de uma coleção planejada e organizada com o maior escrúpulo e com todo o vagar, visando a corresponder não só às necessidades do estudioso como à curiosidade intelectual de todo brasileiro culto pelas coisas e pelo passado do seu país". Na sequência, passava a discorrer sobre os trabalhos a serem nela publicados: memórias, biografias, livros de viagem e de expedições científicas ao Brasil, relatórios de época, "documentos e estudos sobre os vários traços de influência estrangeira [...] que se encontram em nossa formação social e étnica", "estudos documentados sobre as nossas populações atuais", traduções. Todo um material, enfim, "tão rico e de um valor tão 
evidente para a compreensão e a interpretação do nosso passado, dos nossos antecedentes, da nossa vida em seus aspectos atuais mais significativos" (IDEM, p. V-IX).

À primeira vista, a semelhança com a Brasiliana era flagrante. Talvez por isso, como já notou Heloisa Pontes (2001, p. 464), Gilberto Freyre se esforçasse em destacar a sua singularidade, trocando qualquer alusão à agora concorrente pela ênfase no planejamento e na organização de José Olympio. No entanto, a diferença crucial entre elas não estava nesse aspecto, até porque, como Freyre e seus leitores bem sabiam, a série da Nacional também primava por uma estrutura bem-pensada e executada. A essência da nova coleção revelava-se em seu comprometimento com aquilo que trazia já no próprio nome e que era várias vezes repetido no texto de apresentação: o documento. Desencavado do passado ou produzido no presente, em "estado quase bruto" ou analisado de forma criteriosa, ele estaria na base dos trabalhos a serem publicados, como era dito praticamente a cada parágrafo. O propósito era, parece claro, a afirmação de um conhecimento verdadeiro sobre o Brasil, do conhecimento do Brasil real, fundamentado não em reconstruções ou especulações superficiais e estéreis, e sim em interpretações comprováveis a seu respeito. Numa palavra, tratava-se de afirmar o conhecimento científico sobre o Brasil, elaborado por especialistas que davam "vida" aos documentos para juntá-los “à história social do brasileiro”.

Para os leitores da época, não era difícil perceber o quanto tal perspectiva emulava o trabalho do próprio Freyre. Ao contrário, podia-se ouvir com facilidade no prefácio a Raízes do Brasil os ecos de Casa-grande \& senzala e de Sobrados e mucambos (este também publicado em 1936), a começar da atenção dedicada ao caráter histórico das já mencionadas memórias, biografias, livros de viagem e toda "uma variedade de material em grande parte ainda virgem". Também a "história íntima” do Brasil, reivindicada na abertura de sua primeira obra, reaparecia na referência àqueles "que procuram conhecer o passado brasileiro na sua maior intimidade". Ou então, o acento no caráter diversificado da história e na necessidade de abordá-la com "humildade diante dos fatos", porém, sem deixar de quebrar a sua rigidez para assim "humanizá-los", ideias essas que perpassavam todos os textos em questão, ora de modo explícito, ora implícito (FREYRE, 1936, p. 22, passim; FREYRE, 1985, p. 51). 
Por conseguinte, nada mais lógico que os nomes elencados, no mesmo texto, como colaboradores da coleção tivessem também grande afinidade intelectual ou profissional com seu diretor. Tal qual Sérgio Buarque, muitos deles eram seus amigos pessoais, como Octavio Tarquínio de Sousa, Olívio Montenegro, Afonso Arinos de Melo Franco, Rüdiger Bilden, Manuel S. Cardoso, entre outros. Alguns, inclusive, já haviam merecido menção nos trabalhos anteriores de Freyre, tanto pela ajuda e amizade quanto pela importância de seus estudos em desenvolvimento, os mesmos que agora se anunciavam para breve na Documentos Brasileiros. Dos que não eram tão próximos, havia pesquisadores notórios pelo seu domínio de temas específicos, em geral mais velhos e institucionalmente estabelecidos, como Rodolfo Garcia e Afonso d'Escragnolle Taunay; professores-investigadores ligados às modernas ciências sociais e ao meio acadêmico, casos de Heloisa Alberto Torres e de Donald Pierson, e, o que talvez pudesse parecer surpreendente aos leitores da época, até um autor duramente criticado em Casagrande \& senzala: Oliveira Vianna. Finalmente, mesmo estrangeiros como Roy Nash, Theodor Koch-Grünberg, Konrad Guenther, J. F. Normano, Pierre Deffontaines e Percy Alvin Martin, cujas obras se pretendia traduzir, podiam ser encontrados quase todos pelas páginas dos dois livros de Gilberto Freyre, a ajudá-lo a fundamentar suas análises.

A arquitetura da coleção mostrava-se, assim, uma bem-planejada extensão da casa-grande intelectual construída pelo historiador-sociólogo pernambucano. E, em sua própria avaliação, a pedra fundamental fora lançada com sucesso, pois,- em nova carta a José Olympio, datada de 10 de novembro, Freyre lembrava que:

o nosso Lins [José Lins do Rego], que está aqui por uns dias, já lhe mandou dizer por telegrama que a minha impressão do $1^{\circ}$ livro da nossa coleção foi a mesma que a dele: ótima. $V$. está de parabéns. Acho que o tipo do texto - para não falar no feitio da capa, tão feliz - deve ser mantido. É tão claro, sóbrio, elegante. Não tenho dúvidas: vai ser, já é, uma coleção vitoriosa.

A atenção de Freyre ao projeto gráfico do volume inaugural não era gratuita, sequer irrelevante. Como autor, ele tinha plena consciência de que um livro, por melhor que fosse o seu conteúdo, não era apenas texto - e, no caso da coleção, se os textos estavam sob seu controle, o processo que os transformava em livros, não. Diante da alta qualidade material de Raízes do Brasil, sua satisfação estava completa. Além disso, a 
confiança no êxito da série agora Ihe permitia aplicar seu zelo a outras atividades, também importantes para reforçar, ou consolidar, o seu sucesso. Uma delas despontava ao final da mesma carta, quando pedia ao editor que enviasse "os livros da coleção e os de Lins" para o historiador Percy Alvin Martin e para os antropólogos Rüdiger Bilden e Melville J. Herskovits, nos Estados Unidos. Amigos e interlocutores de Freyre, todos os três eram nomes muito respeitados no meio acadêmico daquele país e estudiosos da América Latina e de questões raciais, características que revestiam a cortesia da intenção de divulgar e, pretensamente, legitimar a Documentos Brasileiros entre a moderna ciência social norte-americana, berço intelectual do seu próprio diretor.

Ao lado das relações públicas e da afirmação externa da coleção, havia ainda que dar continuidade à sua edificação, tarefa nada simples. O contato direto ou indireto com potenciais autores, apesar de constante, nem sempre se mostrava frutífero, e por razões às vezes bem prosaicas: em carta de dezembro de 1936 a Freyre, Rodrigo Melo Franco registrava em post-scriptum ainda não ter conseguido falar com Prudente de Morais Neto sobre a possibilidade de ele "escrever uma história da literatura brasileira para os Documentos Brasileiros", mas adiantava achar "pouco provável que ele possa aceitar o convite, pois não tem agora tempo para nada desde que passou a trabalhar como secretário do pai na Light”. Ademais, a desistência de Oliveira Vianna (que, além de mencionado no prefácio de Raízes do Brasil, como visto, tinha o abortado Os tipos étnicos do Brasil também anunciado na contracapa do volume entre os próximos lançamentos da série) demonstrava que nem mesmo o comprometimento prévio de um autor podia garantir o aparecimento de seu livro. Tudo isso sem considerar ainda que não se tratava somente de nomes, pois, tão importante quanto eles, era a sua adequação ao perfil da coleção ou às expectativas de seu diretor (o que, em geral, dava no mesmo), como mostram duas cartas trocadas entre José Olympio e Gilberto Freyre ainda em 1936.

Na primeira, datada de 16 de dezembro, o editor perguntava se poderia "programar na nossa coleção o livro do Eloy Pontes sobre Euclides da Cunha e o do Agripino [Grieco] sobre romancistas. O primeiro do Eloy sobre [Raul] Pompéia foi elogiadíssimo pela crítica, o que v. não ignora. Se saírem fora da coleção não alcançarão o 
mesmo sucesso. Mas você é quem sabe e dirá com a maior franqueza. Nada de constrangimentos". ${ }^{4}$ Três dias depois, Freyre escrevia sua resposta, na qual argumentava:

Quanto aos livros do Eloy e de Agripino, tanto um como o outro têm nome e dariam assim brilho à coleção. Mas é preciso notar o seguinte: a coleção tem o seu caráter, os seus limites, os seus fins precisos e é preciso que o livro que saia como Documentos Brasileiros corresponda àquele caráter e àqueles fins. Se o Euclides do Eloy for como o Pompéia com aquele luxo de documentação virgem -, corresponde. Seria necessário examinar este ponto para lhe poder dar uma resposta conscienciosa. Quanto ao livro de Agripino, temo que, pelo seu caráter de crítica impressionista, não corresponde. Isto nada reflete de desfavorável sobre o livro - é uma questão de ser ou não ser - do ponto de vista, vamos dizer técnico - do caráter da coleção. O próprio livro que Olívio Montenegro está escrevendo receio às vezes que não se preste à coleção - embora seja um livro interessantíssimo, segundo tudo indica (ainda não li). Mas estou falando sobre o caso um pouco aereamente, sem saber ao certo o que são os livros de Eloy e de Agripino. Sobretudo o de Agripino - do qual V. só me dá o título, que fiz supor livro impressionista, no gênero dos que ele escreve admiravelmente e como ninguém no Brasil.

Sem se excluírem entre si, a diferença entre as falas estava no foco que cada uma lançava sobre a Documentos Brasileiros. Para José Olympio, ela era portadora de um valor que se sobrepunha ao dos livros que reunia e, por isso, catalisadora da sua recepção, mesmo em se tratando de autores bem-conhecidos, como era o caso. Para Freyre, esse valor, inegável, não emanava da coleção em si, mas de uma fonte muito mais precisa: a fundamentação criteriosa dos textos nela publicados, a mesma tantas vezes afirmada no prefácio inaugural. Empenhada na divulgação de olhares objetivos e precisos sobre o Brasil, nela não deveria haver lugar para "impressionismos" como o de Agripino Grieco, representativo de uma tradição intelectual que se buscava superar. Pela mesma razão, o trabalho de Eloy Pontes só seria aceito ali se apresentasse a qualidade documental de seu estudo anterior, uma vez que, sem ela, não haveria sentido em acolhê-lo naquele conjunto. Sutilmente, o diretor parecia querer lembrar o editor de que o nome da coleção não era casual, e apresentava-se tão disposto a fazer valer seus princípios orientadores quanto a preservá-la de pretensões meramente comerciais, embora não desprezasse, de modo algum, essa dimensão do seu trabalho.

Paralelamente às discussões acerca da identidade dos Documentos Brasileiros, prosseguia a preparação do seu segundo volume, as memórias do historiador pernambucano Manuel de

4 O referido livro de Eloy Pontes era A vida inquieta de Raul Pompéia, publicado pelo próprio José Olympio em 1935. 
Oliveira Lima (1867-1928), que fora mentor e amigo íntimo de Freyre. O livro, intitulado Memórias (Estas minhas reminiscências...), saiu em março de 1937, com direito a novo elogio do diretor da coleção, que escreve a José Olympio dizendo ter achado "ótima a apresentação das memórias do Oliveira Lima”. Frente ao primeiro volume, as únicas diferenças gráficas estavam na capa, onde o vermelho substituía o verde do filete e das letras do título, e na contracapa, onde uma reunião de “opiniões da crítica brasileira sobre Raízes do Brasil, de Sérgio Buarque de Holanda”, entrava no lugar dos próximos lançamentos da série. Também custava o dobro do preço do anterior, $20 \$ 000$ (vinte mil-réis); porém, isso não chegava a ser um problema. Ainda de acordo com Freyre, referindo-se à capital pernambucana, as Memórias "têm tido aqui uma saída extraordinária. Não param nas livrarias. A procura é enorme" - situação que, segundo o Anuário Brasileiro de Literatura (1938, p. 401), se repetia no Rio de Janeiro e, é provável, em outros lugares do País.

Mas o aspecto mais importante que o segundo volume parece marcar para a coleção é o início de um novo ritmo em sua produção, mais acelerado e regular a partir de então. Se entre o lançamento do livro de Sérgio Buarque e o de Oliveira Lima houvera um hiato de cinco longos meses, no decorrer de 1937 seriam publicados nada menos que cinco outros títulos: pela ordem, Bernardo Pereira de Vasconcellos e seu tempo, de Octavio Tarquínio de Sousa; Nordeste, de Freyre; O Outro Nordeste, de Djacir Meneses; No rolar do tempo, de Alberto Rangel e O índio brasileiro e a Revolução Francesa, de Afonso Arinos de Melo Franco. Depois, até julho de 1938, sairiam o estudo do historiador baiano Luis Viana Filho sobre A Sabinada - A república baiana de 1837, a biografia Brasílio Machado, do historiador paulista Alcântara Machado, e, a despeito dos temores anteriormente manifestados pelo diretor, o livro de Olívio Montenegro, O romance brasileiro. De volume em volume, a Documentos Brasileiros tomava forma cada vez mais concreta, uma forma que, articulada por e em torno de Gilberto Freyre, fazia com que o conhecimento do Brasil passasse por Recife.

A dinâmica da coleção parecia, assim, materializar com perfeição as expectativas sobre ela projetadas. Além do mais, a conquista da estabilidade também lhe conferia um brilho que, embora continuasse a se beneficiar da importância dos nomes de seu diretor e de seu editor, já podia ser considerado próprio, à semelhança da Brasiliana. Com tudo correndo tão bem, seria difícil imaginar que algo abalasse o seu funcionamento. No entanto, como costuma acontecer com as grandes surpresas, elas vêm de onde menos se espera; no caso, do próprio Freyre, que, em meados de 1938, tomou a decisão de deixar seu posto, motivado, como explicou ao amigo José Lins do Rego em carta datada de 12 de agosto, pelo seu distanciamento do Rio de Janeiro e mais "uma série de coisas inevitáveis". 
Embora a tal "série de coisas inevitáveis" fosse um tanto obscura, o argumento da distância entre Recife e o Rio era de fato considerável, à medida que o impedia de ser mais ágil na condução da coleção e de acompanhar diretamente o seu processo de produção. Por esse raciocínio, não haveria dúvida de que seu posto seria mais bem ocupado por alguém que pudesse ser mais presente e, portanto, mais eficaz no trato com autores e com o editor. De todo modo, a saída não significava uma ruptura nem com José Olympio, nem com a Documentos Brasileiros, que, àquela altura, alcançava seu décimo título e tinha vários outros já aprovados, entre eles o outrora discutido trabalho de Eloy Pontes sobre Euclides da Cunha e duas reedições do próprio Euclides, Canudos (Diário de uma expedição) e Peru versus Bolívia. Além disso, seu nome continuaria a aparecer no frontispício dos oito volumes seguintes, adentrando o ano de 1939, enquanto José Olympio buscava alguém para sucedê-lo.

Somente a partir do volume 19, Fronteiras do Brasil no regime colonial, de José Carlos de Macedo Soares, a Coleção Documentos Brasileiros passou a trazer a inscrição “dirigida por Octavio Tarquínio de Sousa". Nascido no Rio de Janeiro em 1889, formado em Direito em 1907 pela Faculdade de Ciências Jurídicas e Sociais do Distrito Federal, o novo diretor era então vicepresidente do Tribunal de Contas da União, posição que mantinha desde 1937, após ter passado pela presidência nos dois anos anteriores. Muito mais destacadas, porém, eram as suas atividades intelectuais na década de 1930. Além de membro do Instituto Histórico e Geográfico Brasileiro e da Sociedade Felipe de Oliveira, colaborava com vários jornais e revistas do eixo Rio-São Paulo; fora crítico literário do prestigioso O Jornal (RJ) entre 1935 e 1937 e em 1938 assumira a direção da Revista do Brasil em seu relançamento, agora vinculada aos Diários Associados de Assis Chateaubriand. Como autor, publicara o romance Monólogo das coisas, em 1914, e uma elogiada tradução do poema Rubaiyat, de Omar Khayyam, em 1928, mas, desde o trabalho A mentalidade da Constituinte, de 1931, dedicou-se por completo à história do Brasil.

Todas essas credenciais, somadas à amizade com Gilberto Freyre e José Olympio e ao fato de ter dois livros publicados na coleção, faziam de Octavio Tarquínio um nome ideal para assumir a Documentos Brasileiros. E se seu Bernardo Pereira de Vasconcellos e seu tempo tivera a honra de ser dos primeiros da série, História de dois golpes de Estado seria, por coincidência, o último volume editado sob a direção de Gilberto Freyre, em abril de 1939. Daí por diante, um novo cenário iria se desenhar à sombra das palmeiras de Santa Rosa. Totalmente à vontade em sua nova função, Octavio Tarquínio assumiu os poderes do cargo sem hesitar, a ponto de vetar, logo ao assumi-lo, a publicação de um livro sugerido pelo próprio Gilberto Freyre. Esta situação voltaria a se repetir dois meses depois, quando devolveu a José Olympio os originais de uma obra sobre 
Tobias Barreto, a ele confiados "pelo nosso Gilberto", apresentando ao editor, em carta escrita em 2 de junho de 1939, um argumento sumário e fatídico: "penso que não convém à coleção 'Documentos Brasileiros”'.

À maneira do autor de Casa-grande \& senzala, o ministro-historiador também tinha interesse em projetar sobre a coleção as suas concepções acerca do conhecimento do Brasil, em geral, e da história, em particular. Nos livros de sua autoria, era patente a predileção pelos acontecimentos e, principalmente, pelos personagens da política imperial em torno do período das Regências. Para ele, o estudo biográfico era um privilegiado meio de acesso a toda uma época, percebendo "nas narrativas de vida de seus biografados a possibilidade de construir análises históricas decifradoras e atualizadoras dos problemas nacionais", como já observou Márcia de Almeida Gonçalves (2003, p. 88). Mas, para que tal possibilidade se realizasse, era fundamental obedecer a alguns critérios, que garantissem o máximo de objetividade possível para situar o homem no meio histórico e, ao mesmo tempo, "fazer um pouco de introspecção social e de reconstituição psicológica".

Tal perspectiva, portanto, distanciava-se muito das tradicionais narrativas laudatórias dos "grandes feitos de grandes homens", produzidas tanto por historiadores quanto por literatos. $\mathrm{Na}$ visão de Octavio Tarquínio, o valor historiográfico das biografias estava na contextualização rigorosa, sempre fundamentada em documentos, que elas tinham a obrigação de empreender a fim de entender o indivíduo, suas ações, suas contradições, sem sobrepô-lo a seu tempo ou consagrar-lhe características "heróicas". Nesse sentido, ele se alinhava a autores que, em diferentes lugares, inclusive no Brasil, empenhavam-se pela renovação do próprio gênero, tendo à frente André Maurois, Emil Ludwig e Lytton Strachey. Com sua ascensão ao comando da Documentos Brasileiros, tentativas semelhantes passaram a contar com um aliado sempre disposto a lhes dar abrigo: não é casual, certamente, que 13 dos 29 volumes lançados entre 1940 e 1945 tenham sido de caráter biográfico ou memorialístico, incluindo dois livros de sua própria autoria - Diogo Antônio Feijó, de 1942, e José Bonifácio, de 1945.

Junto à incorporação da biografia, o novo diretor soube também consolidar o prestígio da coleção, que, logo no início da década de 1940, já podia ser comparada à série da Companhia Editora Nacional, embora fosse muito mais recente e muito menos vultosa. É o que se depreende de uma pequena nota publicada na Revista do Brasil, em maio de 1942, a qual dizia ser "bastante significativo o gosto do público literário do país pelas obras de estudo relativas à vida brasileira nos seus vários aspectos", percebido pelo "sucesso de algumas coleções especializadas 
Olympio, porém, “não lhe fica[va] atrás", pois, mesmo contando com menos de 35 obras, todas haviam sido "escolhidas com o maior rigor, e quase todas [eram] de singular importância do ponto de vista histórico, sociológico ou literário" (REVISTA DO BRASIL, maio de 1942, p. 88).

Rapidamente, Octavio Tarquínio de Sousa afirmara-se como um ótimo administrador do edifício arquitetado e levantado por José Olympio e Gilberto Freyre. Estes, por sua vez, continuavam muito participativos em relação à Documentos Brasileiros. No caso de José Olympio, o dever do ofício e os cuidados que a ela dedicava o levavam a fazer muito mais que referendar ou não as ideias e decisões do diretor, procurando também atrair autores, sempre que possível. Já Freyre agia sem muita diferença dos tempos em que a tinha sob sua responsabilidade: fazia contato com potenciais autores e incentivava outros a escrever, indicava livros e remetia originais para o Rio de Janeiro, discutia ora com o diretor, ora com o editor a publicação dos seus próprios títulos. Tudo, em larga medida, estimulado e legitimado pelos próprios Octavio Tarquínio e José Olympio, que, ao menos aparentemente, não se sentiam ofendidos com tantas intervenções.

Nem haveria razão para tanto, aliás, pois essa triangulação era favorável a todos, principalmente para a coleção. O melhor exemplo disso talvez seja dado pela trajetória editorial de Casa-grande \& senzala. Após uma longa briga de Gilberto Freyre com seu primeiro editor, o poeta Augusto Frederico Schmidt, que se arrastou por anos e só se resolveu nos tribunais, a obra passou às mãos de José Olympio, e de pronto foi encabeçar a lista dos próximos lançamentos da Coleção Documentos Brasileiros. A publicação ainda demoraria mais dois anos, mas, nas mãos do melhor editor do País, o mais importante livro da época, escrito por um dos maiores autores nacionais, chegava assim àquele que parecia ser o seu devido lugar. A coleção, por seu lado, demonstrava-se plenamente consagrada ao acolher sua fonte de inspiração intelectual, ela que fora orientada, ao menos no início, pelas ideias e pelas propostas do livro de estreia de Gilberto Freyre. Subjacente a esse encontro, ocorre uma inversão de papéis sutil, quase imperceptível: a identidade própria conquistada pela coleção a dotara de autonomia suficiente para se impor às origens, transformando esse livro em "apenas" mais um de seus volumes.

Essa identidade própria permitia também algumas iniciativas pouco comuns ao mercado editorial da época, como abrigar títulos dedicados a estudos de história "das ideias", tema ainda hoje não muito familiar à nossa tradição intelectual. $O$ primeiro deles foi $O$ índio brasileiro e a 
Revolução Francesa, de Afonso Arinos de Melo Franco, publicado logo no início da série, em 1937. Vinte anos depois, a expressão "história das ideias" voltaria a aparecer, desta vez já no título do livro de João Cruz Costa, Contribuição à história das idéias no Brasil, cujo complemento, "O desenvolvimento da filosofia no Brasil e a evolução histórica nacional”, delineava melhor o seu conteúdo. No ano seguinte, o volume A democracia coroada, de João Camilo de Oliveira Torres, aparecia com a pretensão de, segundo o próprio autor, "dentro dos métodos e intenções da disciplina que se intitula a 'história das idéias', analisar os diferentes sistemas ideológicos que exerceram influência no Brasil, seja em seu desenvolvimento político, como no caso presente, seja na formação espiritual, seja ainda na vida religiosa ou social" (OLIVEIRA TORRES, 1958, p. 15).

Como se vê, um longo hiato temporal separava tais obras, que, além disso, apresentavam perspectivas analíticas discrepantes. Longe de ser mero detalhe, ambas as características sugerem que, antes de representar uma tendência bem delineada da nova historiografia brasileira, as "idéias" serviam muito mais como um rótulo para classificar trabalhos de temática que pouco se encaixavam nos compartimentos estabelecidos pelas formas habituais de se analisar o Brasil. Por isso mesmo, não deixa de ser curioso notar que, enquanto a coleção abria suas portas a essa abordagem tão imprecisa, outra novidade, esta mais abrangente e muito mais bem-definida, seria por ela ignorada: o marxismo. Deliberadamente ignorada, talvez seja possível dizer, já que, desde o início da década de 1930, nossos circuitos intelectuais mostravam-se atentos à emergência da interpretação materialista da história do Brasil, como demonstrava a intensa difusão de obras marxistas, clássicas e contemporâneas, em geral realizada por pequenas editoras e com sucesso comercial considerável, segundo o historiador Edgard Carone (2004, p. 63).

Nada disso, contudo, tornaria a Documentos Brasileiros sensível a autores comprometidos com a interpretação materialista da história e da realidade, algo que decerto não deve ser creditado a um possível conservadorismo, muito menos a reacionarismo, do editor. De postura liberal, José Olympio era um dos principais fomentadores do novo e crítico romance social que surgia à época no País, e ainda daria guarida profissional a autores assumidamente de esquerda, perseguidos pela ditadura do Estado Novo, como Graciliano Ramos e Jorge Amado. Ademais, a crescente tensão política entre 1935 e 1937 e, depois, a institucionalização da censura fizeram-no sofrer bastante com a violência contra a livre manifestação da cultura e do pensamento, que, segundo Laurence Hallewell (2005, p. 455), retaliava tanto os romances tidos por "comunistas" que publicava quanto as suas edições de livros integralistas, que defendiam "o tipo errado de fascismo". 
Como hipótese, talvez seja possível atribuir tal ausência ao perfil de seus respectivos diretores. No caso de Gilberto Freyre, sua reticência em relação ao materialismo históricodialético se explicitara já nas páginas iniciais de Casa-grande \& senzala, onde, apesar de não ser negado de todo, fora caracterizado como "tantas vezes exagerado nas suas generalizações principalmente em trabalhos de sectários e fanáticos". Já com relação a Octavio Tarquínio, sua predileção pelo biográfico necessariamente implicava algumas diferenças ante a interpretação materialista da história. Estas, no entanto, não o colocavam em franca oposição ao marxismo, até porque seu propósito era sempre, como já foi notado, o de entender o homem em si mesmo e em relação com seu meio e seu momento, como constatou Márcia de Almeida Gonçalves (2003, p. 290) ao analisar a introdução à História dos fundadores do Império do Brasil, em que o próprio Marx é discutido por Tarquínio, para quem "a luta de classes não implicava a negação da interferência de grandes personalidades, dotadas de qualidades morais e intelectuais, no desenvolvimento das sociedades". Mesmo assim, a tolerância muito maior que a de Freyre não foi suficiente para abrir a coleção à esquerda; ao menos, justiça seja feita, a direita também nunca teve nela grande expressão, o que demonstra uma vez mais o compromisso do editor e, por extensão, de seus diretores, com a cultura, não com a política.

Assim, enquanto corriam os anos 1930 e 1940 e o País vivia grandes transformações, tanto materiais quanto mentais, no sentido de sua modernização, a Documentos Brasileiros se constituiu como marco de uma intelectualidade também em mudança. Em fins da década de 1950, porém, já era possível sentir que sua fórmula dava sinais de esgotamento. Em texto de 1958, o historiador José Honório Rodrigues notava, de modo genérico, que as coleções dedicadas ao exame do Brasil "tinham o dever de provocar um pensamento mais pragmatista, em que o presente, com seus problemas e temas, fosse o foco em que se projetasse a luz do passado". No entanto, continuava ele, a "história historizante, história puramente descritiva, história clássica como um relógio de repetição", havia tomado de assalto tais "brasilianas", que teriam passado "a debater os mesmos problemas e a discutir as mesmas teses, apenas porque o especialismo erudito descobrira mais uma miúda novidade ou uma palavra diferente da mesma personagem" (RODRIGUES, 1965, p. 18).

Novos interesses já se divisavam então no horizonte do mundo intelectual nativo, e eles não eram mais os mesmos da década de 1930. Outros canais de manifestação, como a universidade, passaram a ocupar o espaço da produção e circulação de ideias, e mesmo o mercado editorial, muito em função dessa dinâmica, passava por redefinições, deixando a generalização rumo à segmentação. A partir daí, com o campo das Ciências Humanas e Sociais 
cada vez mais consolidado e institucionalizado, novos modelos interpretativos e explicativos da realidade entrariam em cena, acompanhados de novos projetos editoriais correspondentes como a Coleção Corpo e Alma do Brasil, ou, pouco mais tarde, a História Geral da Civilização Brasileira, ambas editadas pela DIFEL - e mesmo de uma renovada política editorial - como a de Ênio Silveira, na Editora Civilização Brasileira.

Pouco a pouco, a Coleção Documentos Brasileiros e a própria Editora José Olympio vão perdendo sua hegemonia: no caso da primeira, junto à intelectualidade; no caso da segunda, junto ao mercado. Por mais que resistissem, e ambas resistiram muito a incontáveis dificuldades, parecia que o tempo de sua atuação civilizadora, tal como idealizado pelo editor, já havia passado. Seu papel fora cumprido. Mais importante, fora cumprido muito bem, como Otto Maria Carpeaux bem retratou em um belo texto sobre Tomás Santa Rosa, escrito ainda no início dos anos 1950. Parodiando uma sátira de Mark Twain, o crítico e escritor criava uma história na qual, "no ano 9000 da nossa era, os arqueólogos começaram a escavar as ruínas do Rio de Janeiro", descobrindo "em certas cavernas provavelmente dedicadas ao culto de São José numerosas folhas de papel de péssima qualidade", em cujas capas sempre aparecia "o mesmo hieróglifo misterioso: 'SR'”. Curiosos e dedicados em decifrar o significado dessas duas letras, esses arqueólogos do futuro lançaram-se em investigações e hipóteses, uma delas que dizia tratar-se "de um personagem semi-mitológico, de uma condensação folclórica dos traços característicos do homo brasiliensis". E continuava:

Nessa altura apareceu o professor Sicrano, apresentando ao mundo científico descoberta sensacional: uma coleção de obras, evidentemente escritas por autores diferentes, mas todas assinadas pelo misterioso "SR". Chamava-se a coleção "Documentos Brasileiros". O estado de conservação das capas não era muito satisfatório, devido à qualidade do papel, de modo que se repetiu o caso do "grande rei Smith" no conto de Mark Twain: os estudiosos, evocando o costume dos romanos de datar os documentos conforme os nomes dos cônsules do ano, atribuíram a coleção inteira à "época de José Olympio", que teria sido in illo tempore o rei do Rio de Janeiro. Vários autores da coleção podiam ser identificados: Lucia Miguel-Pereira, biografando um poeta em cujos versos aparece um pássaro mitológico chamado "Sabiá"; Octavio Tarquínio de Sousa, que viveu, conforme os documentos, no século XX, embora alguns historiadores teimem em incluí-lo entre as grandes personalidades da época da Regência; Álvaro Lins, conhecido nos anais da literatura como crítico impiedoso, aí porém metido na história dos compromissos diplomáticos; Gilberto Freyre, dono indiscutido da casagrande da sociologia brasileira; Afonso Arinos de Melo Franco, índio mineiro que participou da Revolução Francesa e provavelmente de mais outras revoluções; e Sérgio Buarque de Holanda, que chegou a 
desenterrar as próprias raízes do Brasil. Para todos esses autores e obras, por mais diferentes que tenham sido, criou "SR" o símbolo comum que distingue, invariável e inconfundivelmente, os volumes todos da Coleção Documentos Brasileiros, símbolo de significação profunda e simplicidade surpreendente: uma palmeira. A árvore típica, cujas raízes se confundem com as próprias raízes do Brasil; a árvore que deu sombra à casa-grande do senhor e à senzala dos escravos; a árvore que, através das vicissitudes da história do Brasil, sombreou o cemitério das derrotas e se hasteou, às vezes, como bandeira da vitória; a palmeira bem brasileira, as raízes na terra e a coroa no alto, na região da poesia (CARPEAUX, 1953, p. 198-199).

Mirando as palavras de Carpeaux com o devido distanciamento propiciado pelo tempo, é possível dizer que, à sombra da palmeira plantada por José Olympio e zelosamente cultivada por Gilberto Freyre e Octavio Tarquínio de Sousa, uma nova historiografia brasileira encontrou solo fértil para florescer. Um solo bem diferente daquele encontrado nos Institutos Históricos e Geográficos - fosse o IHGB, fossem os regionais -, já cansados pela semeadura oitocentista, e, ao mesmo tempo, diferente também da terra nova representada pelas nascentes faculdades de Filosofia. E, como em tantas outras situações, mostram-se, mais uma vez ,válidas as palavras de Robert Darnton (1990, p. 131), para quem “os livros não se limitam a relatar a história: eles a fazem”.

\section{Referências}

\section{a) Documentais}

BRASIL. Diario Official dos Estados Unidos do Brasil, 19 set. 1936. Disponível em: <http://www.jusbrasil.com.br/diarios/2258672/dou-secao-1-19-09-1936-pg-1/pdfView>. Acesso em: 30 abr. 2013.

Correspondência passiva de José Olympio e da Livraria José Olympio Editora. Acervo José Olympio. Arquivo-Museu de Literatura Brasileira da Fundação Casa de Rui Barbosa, Rio de Janeiro/RJ.

Correspondência passiva de Gilberto Freyre. Fundação Gilberto Freyre, Recife/PE.

\section{b) Bibliográficas}

ANUÁRIO Brasileiro de Literatura. A Coleção “Brasiliana" comemorando o seu $100^{\circ}$ volume! Rio de Janeiro: Irmãos Pongetti, 2, 1938. p. 304. 
ANUÁRIO Brasileiro de Literatura. O que se lê no Brasil. Rio de Janeiro: Irmãos Pongetti, 2, 1938. p. 401-407.

CARONE, Edgard. Leituras marxistas e outros estudos. São Paulo: Xamã, 2004.

CARPEAUX, Otto Maria. Retratos e leituras. Rio de Janeiro: Edição da Organização Simões, 1953.

DARNTON, Robert. O beijo de Lamourette. Mídia, cultura e revolução. São Paulo: Companhia das Letras, 1990.

FREYRE, Gilberto. Casa-grande \& senzala. 2. ed. Rio de Janeiro: Schmidt, 1936.

. Documentos Brasileiros. In: HOLANDA, Sérgio Buarque de. Raízes do Brasil. Rio de Janeiro: José Olympio, 1936. p. V-IX.

. Sobrados e mucambos. 7. ed. Rio de Janeiro: José Olympio, 1985.

GONÇALVES, Márcia de Almeida. Em terreno movediço. Biografia e história na obra de Octavio Tarquínio de Sousa. 2003. Tese (Doutorado em História Social) - FFLCH - USP - São Paulo, (publicada em livro com o mesmo título - Rio de Janeiro: EdUERJ, 2010).

HALLEWELL, Laurence. O livro no Brasil. 2. ed. São Paulo: Edusp, 2005.

LIMA, Sônia Maria van Dijck e FIGUEIREDO JUNIOR, Nestor. De Gilberto Freyre para José Lins do Rego. In: GALVÃO, Walnice Nogueira \& GOTLIB, Nádia Battella (Org.). Prezado senhor, prezada senhora. Estudos sobre cartas. São Paulo: Companhia das Letras, 2000. p. 241-250.

OLIVEIRA TORRES, João Camilo de. A democracia coroada. Rio de Janeiro: José Olympio, 1958.

PONTES, Heloisa. Retratos do Brasil: editores, editoras e "coleções Brasiliana" nas décadas de 30, 40 e 50. In: MICELI, Sergio (Org.). História das Ciências Sociais no Brasil. v. 1. 2. ed. São Paulo: Editora Sumaré, 2001. p. 419-476.

REVISTA do Brasil. Livros sobre o Brasil. Rio de Janeiro, a. V, n. 43, mai. 1942. p. 88.

RODRIGUES, José Honório. História e historiadores do Brasil. Rio de Janeiro: Fulgor, 1965.

VILLAÇA, Antônio Carlos. José Olympio: O descobridor de escritores. Rio de Janeiro: Thex, 2001. 
Escrever textos, editar livros, fazer história: a coleção documentos brasileiros e as transformações da historiografia nacional (1936-1960)

Fábio Franzini

Recebido em: 03/02/2013 Aprovado em: 23/04/2013

Universidade do Estado de Santa Catarina - UDESC

Programa de Pós-Graduação em História - PPGH

Revista Tempo e Argumento

Volume 05 - Número 09 - Ano 2013

tempoeargumento@gmail.com 